\section{A brainstem anosognosia of hemiparesis}

\author{
Kazuo Abe, ${ }^{1,2}$ Kiyoka Yamamoto, ${ }^{2}$ \\ Yutaka Uchida ${ }^{2}$
}

'Konan Women's University, Department of Nursing and Rehabilitation; ${ }^{2}$ Konan

Hospital, Department of Neurology and

Rehabilitation Center, Kobe, Japan

\section{Abstract}

A woman had anosognosia for hemiplegia as a manifestation of brainstem infarction. She had no mental or neuropsychological disturbances, and had involvement of the brainstem in the frontal/parietal-subcortical circuits to the right cerebral hemisphere. Brainstem lesions that disrupt frontal/parietal-subcortical areas may affect anosognosia for hemiplegia.

\section{Introduction}

Babinski ${ }^{1}$ is usually credited with introducing the term anosognosia, which he used to describe a patient's lack of awareness of neuralgic deficits, such as hemiplegia. Gerstman ${ }^{2}$ reported a group of patients affected with cerebral hemiplegia, usually of the left side, that showed the strange feature of lack of awareness of their own deficits. Anosognosia for hemiplegia is almost exclusively found in patients with right-side cerebral lesions, although it is possible that some patients with comparable left-side cerebral lesions also might not acknowledge their weakness if aphasia did not limit their communications. Some patients with anosognosia not only do not mention weakness when asked general questions about their functioning but also continue to deny any deficits even after they fail to follow instructions to use the paralyzed limbs. Right hemisphere damage is often associated with euphoria or indifference characterized by minimization of the importance of symptoms, reduced emotional responses, and inappropriate elation. Patients with anosognosia usually have severe hemiplegia, severe sensory loss, and various other findings, including motor impersistence, constructional apraxia, and neglect. ${ }^{34}$ Persistent anosognosia after acute lesions occurs almost exclusively in the cerebral hemisphere, especially in the nondominant one,${ }^{5-8}$ and anosognosia after a brainstem lesion is very rare. ${ }^{8.10}$ We describe here our experience of a patient with persistent anosognosia of hemiparesis after a brainstem infarction and discuss the pathogenesis of anosognosia.

\section{Case Report}

An 87-year old woman was in generally good condition but suffered from mild orthostatic changes. Suddenly, she developed left-hemiplegia accompanied by sensory disturbances. In the acute stage, she was oriented with lefthemiparesis and sensory deficits and was scored 7 by the NIH Stroke Scale (NIHSS). However, she denied her paresis even though she could support her weight with her left lower limb. She looked euphoric and seemed indifferent to her paresis. She showed no signs of global reasoning or language problems and was able to carry out several activities. She was scored 26 by mini mental state examination (MMSE). ${ }^{11}$ Although three months after the attack her deficits had gradually improved to only mild lefthemiparesis, she could barely walk without assistance. Nevertheless, she still denied her paresis. MRI images obtained three months after the stroke showed an abnormal intensity lesion involving the right cerebral peduncle and upper part of the pons (Figure 1). Routine neurological examination findings indicated a leftsided paralysis of the upper and lower limb. The patient was mildly dysarthric with anosognosia for her hemiplegia but without unilateral neglect and no visual field defect was elicited.

\section{Discussion}

A failure of awareness of deficit or anosognosia is frequently reported following right hemisphere damage and can also be seen in patients with global cognitive impairment from degenerative causes such as Alzheimer's disease (AD). When functional decline starts in $\mathrm{AD}$, lack of awareness of this symptom is

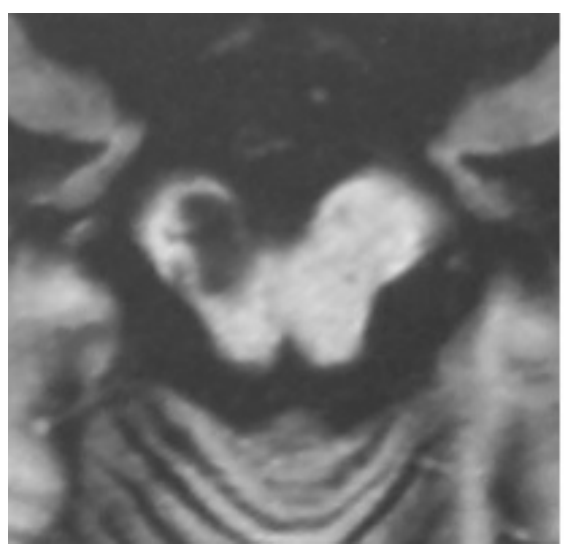

Figure 1. A brain MRI was performed with a 3.0 T system (Achieve; Philips Medical Systems, Eindhoven, The Netherlands) using a standard head coil. A T1-weighted inversion recovery $(\mathrm{TE} / \mathrm{TR}=2000 / 20 \mathrm{msec}, \mathrm{TI}=900 \mathrm{msec})$ image showed a hypo intensity lesion in the medial midbrain (left) and the lesion showed high intensity in a T2-weighted spin echo $(\mathrm{TE} / \mathrm{TR}=4931 / 80 \mathrm{msec})$ image (right).

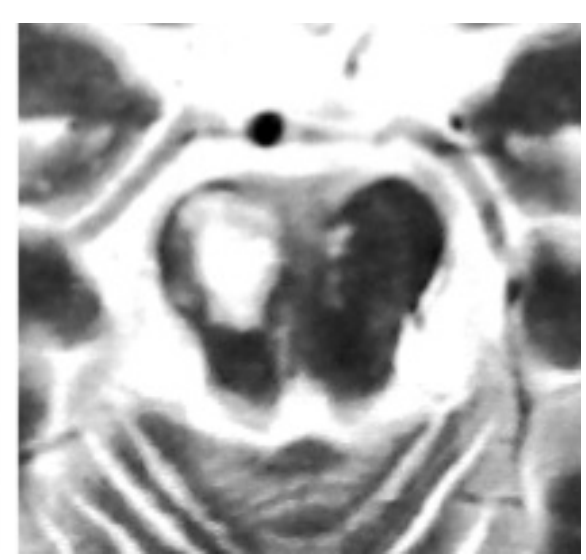

Correspondence: Kazuo Abe, Konan Women's University, Department of Nursing and Rehabilitation 6-2-23 Morikita-cho, HigashinadaKu, Kobe 658-0001, Japan.

E-mail: abeneuro@konan-wu.ac.jp

Key words: anosognosia, hemiparesis, brainstem infarction.

Received for publication: 12 August 2009 Revision received: 28 September 2009. Accepted for publication: 28 September 2009.

This work is licensed under a Creative Commons Attribution 3.0 License (by-nc 3.0).

(C) Copyright K. Abe et al., 2009

Licensee PAGEPress, Italy

Neurology International 2009; 1:e14

doi:10.4081/ni.2009.e14

persistent even when its severity increases with disease progression. When anosognosia appears following an acute lesion it is usually short-lived and in most cases involves unawareness of hemiplegia, but when the acute or post-acute state has passed, patients usually gain awareness of their condition. Anosognosia persisting after acute lesions is less frequent and anosognosia after a brainstem lesion is very rare. ${ }^{5.7}$ Bakchine et al. reported anosognosia for hemiplegia after a brainstem hematoma, but they identified the lesion responsible for anosognosia as concomitant AD. ${ }^{9}$ However, our patient did not show any behavioral features that could have contributed to the anosognosia prior to the attack. Evyapan and Kumral ${ }^{10}$ reported 4 patients with anosognosia for hemiplegia after paramedian pontine infarction and concluded that disruption of frontal/parietal-subcortical circuits activated by brainstem structures may 
contribute to anosognosia. Stuss and Benson ${ }^{12}$ have proposed that certain regions of the frontal lobe may be involved in self-awareness and monitoring of cognitive function. The most recent neuropsychological models have suggested a defect in the feed-forward system, while neuro-anatomical studies have consistently found involvement of the right cerebral hemisphere, particularly the prefrontal and parieto-temporal cortex, as well as the insula and thalamus. ${ }^{8}$

MRIs of our patient showed a lesion corresponding to others previously reported $d^{9,10}$ and including the frontal-pontine and parietal-pontine fibers that connect the frontal lobes. Except for Bakchine's patient, all others had lesions in the frontal-pontine and parietal-pontine fibers connected to the right cerebral hemisphere. Recent neuroimaging results for healthy subjects have demonstrated specific involvement of the posterior insular cortex in the subject's feeling of being versus not being involved in a movement. ${ }^{13}$ Based on this finding, Karnath et al. suggested that the insular cortex is integral to self-awareness and to one's beliefs about the functioning of body parts. ${ }^{14}$ While the region responsible for anosognosia remains controversial, lesions in the connection to the frontal-pontine and parietal-pontine fibers may interfere with information about the body scheme and thus may affect anosognosia from brainstem lesions.

\section{References}

1. Babinski J. Contribution à l'étude des troubles mentaux dans l'hémiplégie organique cérébrale (anosognosie). Revue Neurologique 1914;27:845-8.

2. Gerstamann N. Problems of imperception of disease and impaired body territories with organic lesion. Arch Neurol Psychir 1942;48:890-913.

3. Caplan LR, Bogousslavsky J. Abnormalities of the right cerebral hemisphere. In Stroke syndrome Ed. By Bogousslavsky J and Caplan LR Cambridge University Press, NY 1995 pp162-8.

4. Hier DB, Mondlock J, Caplan LR. Behavioral abnormalities after right hemisphere stroke. Neurology 1983;33:337-44.

5. Berti A, Ladavas E, Della Corte M. Anosognosia for hemiplegia, neglect dyslexia, and drawing neglect: clinical findings and theoretical considerations. J Int Neuropsycho Soci 1996;2:426-40.

6. Minematsu K, Yamaguchi T. Putaminal hemorrhages. Abnormalities of the right cerebral hemisphere. In Stroke syndrome Ed. By Bogousslavsky J and Caplan LR Cambridge University Press, NY 1995 pp372-80.

7. Adair JC, Schwartz RL, Na DL, Fennell E, Gilmore RL, Heilman KM. Anosognosia: examining the disconnection hypothesis. J Neurol Neurosurg Psychiatry 1997;63: 798-800.

8. Orfei MD, Robinson RG, Prigatano GP, et al. Anosognosia for hemiplegia after stroke is a multifaceted phenomenon: a systematic review of the literature. Brain, 2007; 130: 3075-90.

9. Bakchine S, Crassard I, and Seilhan D. Anosognosia for hemiplegia after a brainstem haematoma: a pathological case. J Neurol Neurosurg Psychiatry 1997;63:6867.

10. Evyapan D, Kumral E. Pontine anosognosia for hemiplegia. Neurology 1999; 53:647.

11. Folstein MF, Folstein SE, Mchugh PR. Mini-Mental State Examination: a practical method for grading the mental state of patients for the clinician. J Psychiatr Res 1975;12:189-98

12. Stuss DT, Benson DF. The frontal lobes. New York: Raven Press, 1986.

13. Farrer C, Franck N, Georgieff N, et al. Modulating the experience of agency: a positron emission tomography study. Neuroimage 2003;18:324-33.

14. Karnath HO, Baier B, Nägele T. Awareness of the functioning of one's own limbs mediated by the insular cortex? J Neurosci 2005;25:7134-8. 